\title{
Evisceration of Umbilical Hernia by Impalement: A Case Report
}

\section{Diaby S*, Fall M, Diouf C, Coulibaly Mb, Gueye 0, Bogol J, Ndour 0 and Ngom}

Department of Paediatric Surgery, Senegal

*Corresponding Author: Souleymane Diaby, Department of Paediatric Surgery, Senegal.
Received: May 27, 2021

Published: September 15, 2021

(C) All rights are reserved by Diaby S., et al.

\begin{abstract}
In contrast to the Caucasian child, umbilical hernia can be complicated in $18.5 \%$ of black subjects. In the literature, the main complications described are hernial strangulation and engorgement, which reflect incarceration of the small intestine or omentum through the hernia. Our observation describes a rare complication which is evisceration on umbilical hernia by impalement. This is a 12-year-old female patient with a large umbilical hernia from birth, received at 3 hours of a playful accident at home. Emergency surgical exploration by subumbilical arched approach, ligation and section of the infarcted omentum; longitudinal aponeurography by X-stitches and an umbilical plasty were performed. Progressive feeding was started the next day and discharge was allowed on the third day. The patient received regular care and follow-up. The evolution was unremarkable after the postoperative setback of one month.
\end{abstract}

Keywords: Umbilical Hernia; Evisceration; Impalement

\section{Introduction}

Umbilical hernia is a congenital parietal defect located at the umbilicus, reflecting a delay or absence of closure of the umbilical ring [5].

This area of weakness directly communicates the abdominal contents (small and omentum) with the skin in the form of a variable size, renal, painless and reducible swelling.

Contrary to the Caucasian child, umbilical hernia can be complicated in $18.5 \%$ of the black population [1]. In the literature, the main complications described are hernial strangulation and engorgement, which reflect an incarceration of the small intestine or omentum through the hernia. Our observation describes a rare complication which is evisceration on umbilical hernia by impalement [7].

\section{Case Observation}

This is a 12-year-old girl with a large umbilical hernia since birth. She was received in the emergency department at 3 hours after a playful accident at the family home.

The child would have fallen at home from a height of $120 \mathrm{~cm}$ and landed on the base of the antenna of a parked car, resulting in epiploic evisceration. The first aid was carried out at the health center of the locality from where the child came to us with a venous line and a protective bandage on board a non-medicalized ambulance for a specialized care.

On admission, the clinical examination showed: good general condition, normal colored conjunctiva, temperature $37.1^{\circ} \mathrm{C}$, pulse 100 beats per minute, respiratory rate 24 cycles per minute. 
At the removal of the dressing, we note: an evisceration of the omentum through a median umbilical wound of about $3 \mathrm{~cm}$ in diameter, non hemorrhagic, with linear edges and a diffuse abdominal pain at palpation.

The emergency surgical exploration by sub-umbilical arched approach revealed: an externalization of the omentum over $5 \mathrm{~cm}$ partially infarcted, through a wound of $3 \mathrm{~cm}$ in diameter at the top of the umbilical defect with a neck measuring $4 \mathrm{~cm}$ in diameter (Lassaleta type 3) (Figure 1-3). No effusion or discharge of blood or digestive fluid was noted.

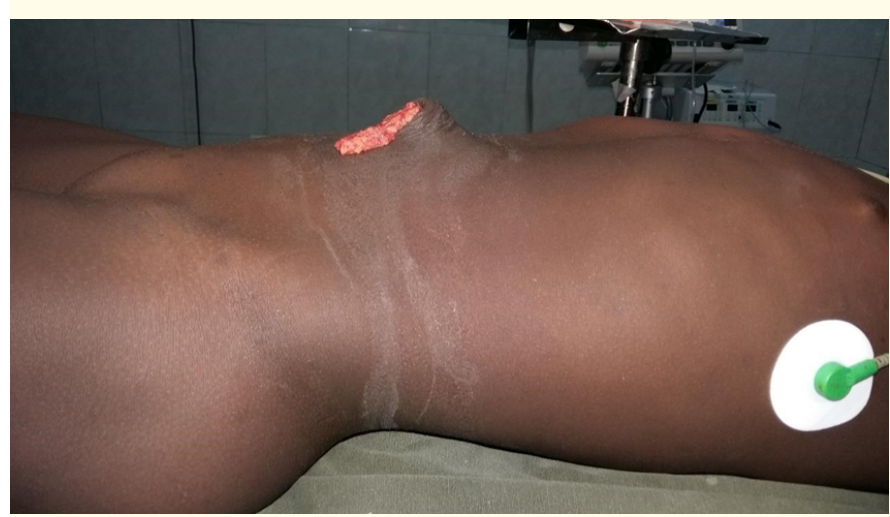

Figure 1: Umbilical wound with epiplocele on side view before surgery.

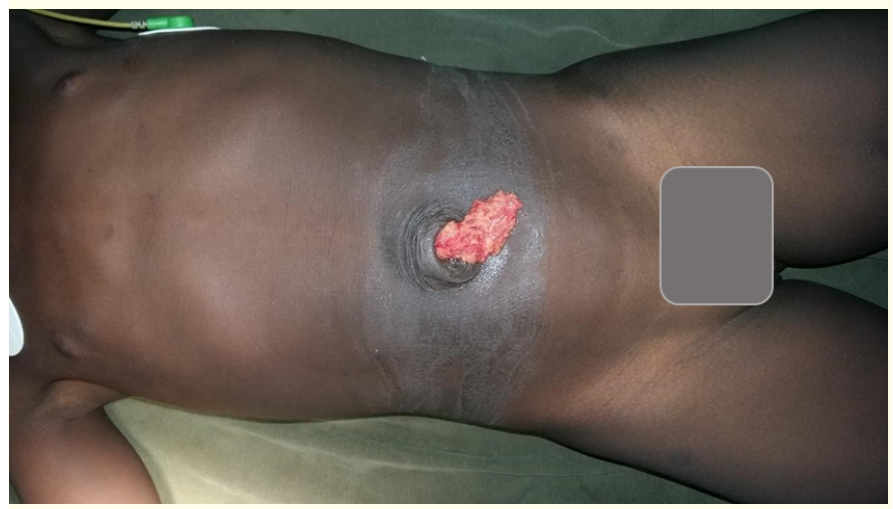

Figure 2: Umbilical wound with epiplocele on front view before the operation.

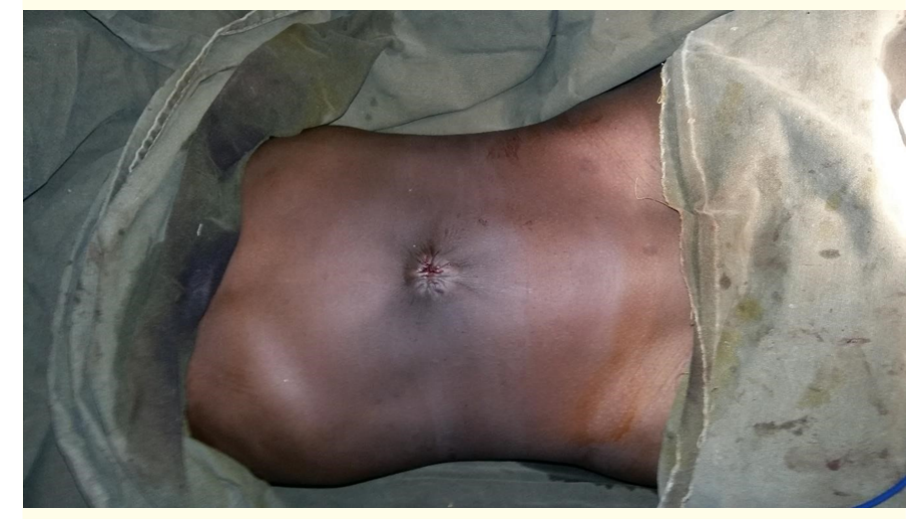

Figure 3: Umbilical aspect in front view after surgery.

The rest of the exploration was normal.

We performed: ligation and section of the infarcted omentum; longitudinal aponeurography with $6 \mathrm{X}$-stitches, reinforced by a $5 / 2$ Vicryl pass-through suture and umbilical plasty.

Progressive feeding was started the next day and discharge was allowed on the third day.

The patient received regular care and follow-up and after a postoperative follow-up of 1 month the evolution was without any particularity.

\section{Discussion}

The majority of umbilical hernias regress spontaneously over time as the defect fascia strengthens, leading to spontaneous closure.

Indications for surgical closure include hernias larger than $2 \mathrm{~cm}$ in diameter at age 2 to 3 years, persistent hernias after age 4 to 5 years as in our case, and those with symptoms of incarceration or recurrent pain.

Traumatic evisceration is a rare occurrence and requires emergency closure of the defect. Several factors are thought to precipitate traumatic rupture: traffic accidents, direct impact, blunt force trauma, fall from a high place.

Traumatic rupture of the umbilical hernia with evisceration in older children is exceptional. Few scientific works have been pub- 
lished on this subject and all were spontaneous ruptures of the umbilical hernia in the newborn or infant $[6,7,11,12]$.

However, this is the first time in our experience that we are confronted with a traumatic rupture of the umbilical hernia with evisceration.

The indication of an emergency surgical exploration is essential. However, the approach varies according to the surgeons. Most authors recommend arciform incisions under, above and on the left side with or without umbilical plasty [12].

Indeed, they allow to reduce the extent of the operative wound and are less invasive. On the other hand, they do not allow a complete exploration of the abdominal cavity.

The surgical exploration is an important time because it allows to confirm the diagnosis but also to eliminate a perforation of a hollow or solid intra-abdominal organ.

The average length of hospitalization does not exceed 3 days in the literature, as was the case in our patient [12]. This is consistent with our study.

In our patient, the evolution was good after one month.

\section{Conclusion}

Post-traumatic evisceration is an exceptional complication of umbilical hernia, but can occur in children. This complication is an additional argument for a systematic cure of umbilical hernias in our context.

\section{Bibliography}

1. Bandré E., et al. "Hernies ombilicales étranglées chez l'enfant au Burkina Faso: différences avec les pays développés". Le Bulletin de la Société de Pathologie Exotique 103 (2010): 100-103.

2. Bikandou G., et al. "Les traumatismes abdominaux de l'enfant au C.H.U. de Brazzaville (à propos de 41 cas)". Medecine d'Afrique Noire 39.1 (1992).

3. Chaumoître K., et al. "Particularités des traumatismes thoraciques et abdominales chez l'enfant". Journal of Radiology 89 (2008): 1871-1888.
4. Goknar N., et al. "Spontaneous evisceration of umbilical hernia in a patient with congenital nephrotic syndrome". Journal of Pakistan Medical Association 67.5 (2017).

5. Harouna Y., et al. "La hernie ombilicale de l'enfant noir africain: aspects cliniques et résultats du traitement à propos de 52 cas". Medecine D'afrique Noire 48.6 (2001).

6. Hulsebos RG., et al. "Perforation of a Congenital Umbilical Hernia in a Patient with Hurler's Syndrome". Journal of Pediatric Surgery 39.9 (2004): 1426-1427.

7. Kittur DH., et al. "Rupture de la hernie ombilicale avec éviscération chez un nouveau-né - un rapport de cas". Journal of Neonatal Surgery 6 (2017): 67.

8. Méfat L and Becmeur F. "Hernie ombilicale de l'enfant". EMC (2007): 40-140.

9. Meyer P., et al. "Traumatismes abdominaux chez l'enfant". EMC (2007).

10. Monneuse YOJ., et al. "Les plaies pénétrantes de l'abdomen, conduite diagnostique et thérapeutique. À propos de 79 patients". Annales de Chirurgie 129.3 (2004): 156-163.

11. Thomson W L., et al. "A literature review of spontaneous evisceration in pediatric umbilical hernias". Pediatric Surgery International 28 (2012): 467-470.

12. Weik J and Moores D. "An unusual case of umbilical hernia rupture with evisceration". Journal of Pediatric Surgery 40 (2005): E33-E35.

Volume 4 Issue 10 October 2021 (C) All rights are reserved by Diaby $S$,., et al. 